\title{
A Novel Efficient L-Lysine Exporter Identified by Functional
}

\section{Metagenomics}

3 Sailesh Malla, Eric van der Helm, Behrooz Darbani, Stefan Wieschalka, Jochen Forster,

5 The Novo Nordisk Foundation Center for Biosustainability, Technical University of

6 Denmark, Kemitorvet 220, 2800 Kgs. Lyngby, Denmark

7

$8 *$ Corresponding author:

9 Prof. Morten O. A. Sommer

10 Email: $\underline{\text { msom@bio.dtu.dk }}$

11 


\section{Abstract}

13 Lack of active export system often limits the industrial bio-based production processes

14 accumulating the intracellular product and hence complexing the purification steps. L-

15 lysine, an essential amino acid, is produced biologically in quantities exceeding two

16 million tons per year; yet, L-lysine production is challenged by efficient export system at

17 high titres during fermentation. To address this issue, new exporter candidates for efficient

18 efflux of L-lysine are needed. Using metagenomic functional selection, we identified 58

19 genes encoded on 28 unique metagenomic fragments from cow gut microbiome library

20 that improved L-lysine tolerance. These genes include a novel putative L-lysine

21 transporter, belonging to a previously uncharacterized EamA superfamily.

22 Characterization using Xenopus oocyte expression system as well as an Escherichia coli

23 host demonstrates activity as a L-lysine transporter. This novel exporter improved L-

24 lysine tolerance in E. coli by $40 \%$ and enhanced the specific productivity of L-lysine in an industrial Corynebacterium glutamicum strain by $12 \%$. Our approach allows the sequence-independent discovery of novel exporters and can be deployed to increase titres and productivity of toxicity-limited bioprocesses.

Keywords: Amino acid, transporter, E.coli, C. glutamicum, Xenopus oocytes 


\section{Introduction}

32 The global chemical industry is transitioning from reliance majorly on petrochemical

33 processes to more sustainable bio-based production. This development holds promise to

34 improve the sustainability of the chemical industry while also reducing the overall

35 production costs of chemical products. In order to establish a cost competitive bioprocess,

36 titers of fermentations frequently exceed $100 \mathrm{~g} / \mathrm{L}$, which leads to a significant stress on

37 the host organism. Indeed, a majority of industrial bioprocesses are limited in production

38 due to several stresses resulting from high product titers.

One of the most significant bio-based chemical products is L-lysine. The global bio-based

L-lysine production now exceeds 2.5 million tons per year, which is estimated to reach 3.0 million tons in 2022 corresponding to 5.6 billion USD of market value according to the current L-lysine market report (Elder, 2019). Industrial L-lysine bioprocesses entirely rely on Corynebacterium glutamicum and Escherichia coli production strains that achieve titers over 1.2 M (Becker and Wittmann, 2012; Lee and Kim, 2015). It was observed that the L-lysine export rate is inhibited by $50 \%$ upon exceeding the extracellular concentration of $400 \mathrm{mM}$ compared to that at $80 \mathrm{mM}$ (Kelle et al., 1996), indicating the substantial inhibition of the L-lysine-specific export in industrial fermentation. Indeed,

49 several studies have demonstrated the benefit of incorporating active efflux systems to 50 address intracellular product accumulation in biobased production (Borodina 2019; 51 Hemberger et al., 2011; Malla et al., 2010). Hence, L-lysine export system is an obvious target to maintain the producer organism at high lysine concentration as well as easing the downstream process. Despite its importance, there are only two identified lysine specific exporters: i) LysE as a member of the lysine efflux permease (LysE; 2.A.75) family

55 (Bellmann et al., 2001; Vrljic et al., 1999); and, ii) lysine outward permease (LysO or 
$56 \mathrm{YbjE}$ in E. coli) (Pathania and Sardesai, 2015). Vrljic et al. (1996) achieved five folds

57 higher lysine export rate upon overexpression of LysE in C. glutamicum (Vrljic et al., 58 1996). Similarly, Yasueda and Gunji have deployed this strategy for ten-fold improvement

59 in L-lysine production by expressing a spontaneously mutated LysE from C. glutamicum

60 in Methylophilis methylotrophus (Gunji and Yasueda, 2006). In addition to the rational

61 engineering of the existing exporters, there is an urgent demand for new genetic building

62 blocks to further improve L-lysine tolerance and production.

63

64 Functional metagenomic selection is an effective approach to discover novel genes and

65 enzymes due to its ability to access the wide range of genetic elements present in a

66 particular environmental niche (Forsberg et al., 2016; Munck et al., 2015; Sommer et al.,

67 2010, 2009). Hence, we set out to use functional metagenomic selection to identify novel

68 L-lysine transporter candidates from a cow fecal library, with the goal of improving

69 industrial L-lysine production (Fig. 1A). Using C13-labeled L-lysine and mRNA

70 expression of the screened transporter in Xenopus oocyte, the transporter candidate was

71 confirmed as L-lysine exporter. Expression of the metagenomic derived L-lysine

72 transporter improved titer and productivity in both Gram-positive and Gram-negative

73 production strains.

75 Materials and methods

76 Bacterial strains, growth conditions and chemicals

77 All bacterial strains, vectors and plasmids used in this study are listed in Table 1. All 78 oligonucleotide primers (synthesized by Integrated DNA Technologies, Inc.) used are 79 presented in Table 2. E. coli strains were routinely cultured at $37^{\circ} \mathrm{C}$ in Luria-Bertani (LB) 80 broth or on agar supplemented with kanamycin $\left(35 \mu \mathrm{g} \mathrm{mL}^{-1}\right)$ when necessary (hereafter 
81 referred as LB-km). For the L-lysine production in E.coli LB as well as M9 minimal media supplemented with $2 \mathrm{gm} / \mathrm{L}$ of yeast extract were used. C. glutamicum strains were cultured in modified CGXII medium (Keilhauer et al., 1993) supplemented with 5\% sucrose, 1\% BHI, 0.5 mM IPTG and kanamycin (when necessary), at $30^{\circ} \mathrm{C}$ and 250 RPM. Growth media were supplemented with $1.5 \%$ agar for plate assays.

DNA manipulations were carried out following standard protocols (Sambrook and Russell, 2001). All chemicals were purchased from Sigma-Aldrich (St. Louis, MO, USA). Restriction enzymes and T4 DNA ligase were purchased from Fermentas (Denmark) and New England Biolabs (Hertfordshire, UK). DNA sequencing was performed using an automated DNA sequence analyzer.

\section{Metagenomic library construction and functional screening for L-lysine}

94 A metagenomic expression library of total DNA extracted from a cow fecal sample was constructed as described previously (Sommer et al., 2009). Briefly, library construction involves i) the isolation of total DNA from $5 \mathrm{~g}$ of fecal material using the PowerMax Soil DNA Isolation Kit (Mobio Laboratories Inc.), ii) fragmentation of extracted DNA into pieces of an average size of $2 \mathrm{~kb}$ by sonication using a Covaris E210 (Massachusetts, USA) followed by end-repair using the End-It end repair kit (Epicentre), iii) blunt-end ligation into the pZE21 MCS1 expression vector with constitutive promoter pLteo-1 (Lutz and Bujard, 1997) at the HincII site using the Fast Link ligation kit (Epicentre), and iv) transformation of the ligated sample into electro-competent E. coli top 10 cells by the standard method (One Shot ${ }^{\circledR}$ TOP10 Electropcomp ${ }^{\mathrm{TM}}$ Cells, Invitrogen). 
105 After electroporation, cells were recovered in $1 \mathrm{ml}$ of SOC medium for $1 \mathrm{~h}$ at $37^{\circ} \mathrm{C}$, and the library was titered by plating out $1 \mu \mathrm{l}, 0.1 \mu \mathrm{l}$ and $0.01 \mu \mathrm{l}$ of recovered cells onto LB-

$107 \mathrm{~km}$ plates. The insert size distribution was estimated by gel electrophoresis of the PCR

108 products obtained by amplifying inserts using primers annealing to the vector backbone

109 flanking the HincII site. The average insert size for the library was $1.7 \mathrm{~kb}$. The total size

110 of the metagenomics library was determined by multiplying the average insert size by the

111 number of colony forming units (CFU) per $\mathrm{ml}\left(5 \times 10^{8} \mathrm{bp}\right)$. The remainder of the recovered

112 cells were inoculated into $10 \mathrm{ml}$ of LB-km liquid media and grown overnight; the library

113 was frozen down in $15 \%$ glycerol and stored at $-80^{\circ} \mathrm{C}$.

115 The E.coli $\mathrm{C} 4860$ strain was used for the functional screening of L-lysine. First, a plasmid

116 prep of the metagenomics library was carried out from the E. coli top10 cells harboring

117 the library. Then, $400 \mathrm{ng}$ of metagenomics plasmid DNA was transformed into electro-

118 competent E. coli $\mathrm{C} 4860$ cells, and the library titer was determined as described above.

119 On the basis of the determined library sizes and the titer of the library, $10^{6}$ cells (i.e., 100

$120 \mu 1$ of the library cells) were plated on LB-km agar supplemented with L-lysine at the

121 selective concentration $(14 \mathrm{~g} / \mathrm{L})$. Plates were incubated at $37^{\circ} \mathrm{C}$, and the growth of colonies

122 (likely lysine-tolerant clones) was assayed after 48-65 h of incubation.

124 The metagenomic inserts present in L-lysine-tolerant clones were Sanger sequenced using 125 the pZE21_F and pZE21_R primer pair, which annealed to the vector backbone. The 126 resulting raw sequencing chromatogram files were analyzed and functionally annotated

127 using the deFUME web server (van der Helm et al., 2015):

128 http://www.cbs.dtu.dk//services/deFUME/. 


\section{Minimum inhibitory concentration (MIC) and IC90 determination}

131 For MIC determination, the E. coli strains were cultured in LB liquid media at $37^{\circ} \mathrm{C}$

132 overnight, and then approximately $1 \times 10^{4}$ cells were inoculated from the overnight cultures

133 into LB liquid media and grown at $30^{\circ} \mathrm{C}$ and $300 \mathrm{RPM}$ in 96 -well microtiter plates

134 containing $150 \mu \mathrm{l}$ of medium per well. MICs were determined using a logarithmic L-

135 lysine (or chemical) concentration gradient with two-fold serial dilutions. Endpoint

136 absorbance measurements $\left(\mathrm{A}_{600 \mathrm{~nm}}\right)$ were taken with a plate reader (Synergy H1, BioTek)

137 after 24 or $48 \mathrm{~h}$ of incubation and were background-subtracted. Growth inhibition of the

138 E. coli strains was plotted against L-lysine (chemical) concentration with a polynomial

139 interpolation between neighboring data points using $\mathrm{R}$ software (http://www.r-

140 project.org). The percentage of inhibition was calculated using the formula: $1-\left[\mathrm{A}_{600 \mathrm{~nm}}\right.$

141 lysine (or chemical) $/ \mathrm{A}_{600 \mathrm{~nm}}$ control]. The inhibitory concentration was defined as the lowest

142 concentration of the chemical that inhibited $90 \%$ of the growth of the strain tested (IC90).

\section{Growth experiments}

145 Single colonies of the tolerant clone(s) harboring transporter homologues were grown 146 overnight at $37^{\circ} \mathrm{C}$ with shaking in liquid LB-km medium. The OD values at $600 \mathrm{~nm}$ $147\left[(\mathrm{OD})_{600 \mathrm{~nm}}\right]$ were determined by 10-fold dilution. Then, the cultures were diluted to adjust 148 the $(\mathrm{OD})_{600 \mathrm{~nm}}$ to 0.1 , and $5 \mu 1$ of each culture was inoculated in $150 \mu 1$ fresh media 149 containing L-lysine ( 0 and $8 \mathrm{~g} / \mathrm{L}$ ) and kanamycin in a 96-well micro-titer plate. The plate 150 was incubated at $37^{\circ} \mathrm{C}$ for $24 \mathrm{~h}$ in an automated spectrophotometer (ELx808, BioTek) that 151 recorded the $(\mathrm{OD})_{630 \mathrm{~nm}}$ at an interval of $60 \mathrm{~min}$. The data were subsequently retrieved and 152 analyzed to determine growth rates. The growth rate data are the average of triplicate 153 experiments, with error bars representing the standard error of the mean (SEM). 


\section{$155 \quad$ PCR and $E$. coli transformation}

156 PCR was performed in a total volume of $50 \mu 1$ under the following DNA amplification

157 conditions: $95^{\circ} \mathrm{C}$ for $5 \mathrm{~min}$, followed by 30 cycles of $95^{\circ} \mathrm{C}$ for $30 \mathrm{sec}, 50-65^{\circ} \mathrm{C}$ for $30 \mathrm{sec}$,

158 and $72^{\circ} \mathrm{C}$ for $1 \mathrm{~min}$, and finally $72^{\circ} \mathrm{C}$ for $5 \mathrm{~min}$. Electrocompetent or chemically

159 competent E. coli cells were transformed with the ligation mixture using a standard

160 protocol and plated onto LB-km agar plates for selection.

161

162 In silico analysis

163 The amino acid sequence of MglE (Metagenomics gene for lysine Export) was analyzed

164 using Interpro (http://www.ebi.ac.uk/interpro/v), its 2D membrane topology was 165 predicted using Phobius (Käll et al., 2007) and visualized using Protter (Omasits et al., 166 2014), and the phylogenetic tree was plotted using iTOL. The UniProtKB database 167 (Consortium, 2014) was accessed on 2016-06-01 to query the closest homologs of MglE. 168 Pfam version 29.0 (December 2015) (Finn et al., 2014) was used to extract the LysE 169 family (Pfam id: PF01810) members. The Maximum Likelihood Phylogenetic tree was 170 constructed using CLC Main Workbench 7 with the Neighbor Joining construction 171 method.

\section{Transport assays in Xenopus oocytes}

173 The Xenopus laevis oocytes were obtained from Ecocyte Bioscience (Germany). Oocytes 174 were kept in Kulori buffer $(\mathrm{pH} 7.4)$ and at $18^{\circ} \mathrm{C}$. A linear cassette (including $\mathrm{T} 7$ promoter, 175 MglE as the gene of interest, and 3'UTR) was amplified from the plasmid pUSER016176 T7-MglE using Phusion Hot Start polymerase (ThermoFisher Scientific) and the primers

177 linear_cassette F and linear_cassette R. The linear cassette was used as template for in178 vitro transcription. Capped cRNAs was synthesized using the mMESSAGE 179 mMACHINE® T7 Transcription Kit (AM1344; ThermoFisher). The quality and quantity 

assay, $50 \mathrm{nl}$ of the 13C-labeled L-lysine stock solution was injected into the oocytes to obtain estimated internal concentrations of $6 \mathrm{mM}$, assuming an after-injection dilution factor of 20 (Darbani et al., 2016). Following four washing steps, each batch of 20 oocytes

$190 \mu \mathrm{l}$ of the medium was collected from each batch with intact oocytes and added onto $70 \mu \mathrm{l}$

191 of $60 \% \mathrm{MeOH}$ before LC-MS analysis. The oocytes were washed four times with Kulori

192 buffer $\mathrm{pH} 7.4$ and intracellular metabolites were extracted in $30 \% \mathrm{MeOH}$ to analyzed on 193 LC-MS.

\section{E. coli double deletion mutant construction}

195 The chromosomal lysine decarboxylases $l d c C$ and cadA in E. coli W3110 were

196 successively knocked out by PCR targeting to create E.coli DMLC strain. The gene

197 disruption process was carried out as described previously using an ampicillin-resistant

198 pSIJ8 helper plasmid containing both the $\lambda$ Red and FLP systems (Jensen et al., 2015).

199 The primer pair IdcC_F2/IdcC_R (situated 64 bp away from the start/stop codon $l d c C$

200 gene) was used to amplify the kanamycin cassette from the genomic DNA of the $l d c C$

201 inframe knocked out Kieo strain b0186 whereas the primer pair CadA_F2/CadA_R

202 (situated $56 \mathrm{bp}$ away from the start/stop codon cadA gene) was used to amplify the

203 kanamycin cassette from the genomic DNA of the cadA inframe knock-out Kieo strain 
204 b4131. These PCR products were used to delete $l d c C$ and $c a d A$ in E. coli W3110 strain.

205 The detail process of construction of E. coli DMLC is given in supplementary materials.

\section{Plasmid construction}

207 Sub-cloning the metagenomic insert implicated in tolerance phenotypes

208 The recombinant plasmids pZE-MglE and pZE0-P-MglE-T were constructed as described

209 below. The construction of recombinant plasmids was verified by both restriction

210 mapping and direct nucleotide sequencing of the respective genes in the recombinant

211 plasmids.

212

213 Using the oligonucleotide pair MglE_F/MglE_R and the pZE-RCL-MglE plasmid as

214 template DNA, the exact orf of the putative carboxylate/amino acid transporter

215 homologue (referred to as MglE) was amplified. The amplicon was purified with a Qiagen

216 PCR purification kit and digested with the restriction enzymes KpnI and HindIII (NEB,

217 UK), followed by ligation using T4 DNA ligase (Fermentas, Denmark) into the

218 corresponding restriction sites of the multiple cloning site (MCS) of the pZE21 vector to

219 construct the recombinant plasmids pZE-MglE.

220

221 To construct the recombinant plasmid pZE0-P-MglE-T, USER cloning was applied. The 222 pZE21-vector backbone without its promoter (pZE0) was amplified using the 223 oligonucleotide pair pZE21_User_F/pZE21_User_R. The putative carboxylate/amino 224 acid transporter homologue and the native promoter and terminator sequences (P-MglE225 T fragment) were amplified from the pZE-RCL-MglE plasmid using the primer pair P226 MglE-T_User_F/P-MglE-T_User_F. The amplified PCR products were ligated into the 227 recombinant plasmid pZE0-P-MglE-T using the recommended standard USER cloning 228 protocol (NEB, UK). 
230 Codon optimized mglE plasmids construction for oocytes expression study

231 For functional analysis of MglE in Xenopus oocytes, we constructed recombinant plasmid

232 pUSER016-pT7-MglE by USER cloning. The pUSER016 vector backbone was digested

233 with PacI for $18 \mathrm{~h}$ and the ends were further nicked with Nt.BbvCI for two hours. The

234 codon optimized $m g l E$ gene (sequence provided in supplementary data) for Xenopus

235 laevis was synthetized along with N-terminal linker sequence- GGCTTAAU and C-

236 terminal linker sequences -ATTAAACC (in the complementary sequence, $\mathrm{T}$ is replaced

237 by $\mathrm{U}$ for pairing with $\mathbf{A}$ ) including uracil with compatible USER sites easing direct cloning

238 into linearized and nicked pUSER016 vector by USER cloning (USER $\left.{ }^{\circledR}, \mathrm{NEB}\right)$, resulting

239 in plasmid pUSER016-pT7-MglE.

Recombinant plasmids with E.coli lysine exporter and homologous genes of mglE.

242 The lysine exporter, $y b j E$, (900 bp, Genbank accession no. CAQ31402) from E.coli BL21

243 (DE3) was amplified using oligonucleotides YbjE-F and YbjE-R. The PCR product of

$244 y b j E$ was cloned into pZE21 vector excised with $K p n I$ and BamHI restriction enzymes to

245 construct pZE-YbjE expression plasmid.

247 Similarly, four $m g l E$ homologous genes; i) Gene1 (891 bp, 82\% identity, Genbank 248 accession no. CDC57518) from Bacteroides coprophilus CAG:333, ii) Gene2 (891 bp,

249 78\% identity, Genbank accession no. WP_018711839) from Bacteroides barnesiae, iii)

250 Gene3 (870 bp, 54\% identity, Genbank accession no. CDC66277) from Bacteroides sp.

251 CAG:770, iv) Gene4 (912 bp, 43\% identity, Genbank accession no. CCZ76555) from

252 Alistipes finegoldii CAG, were synthetized along with N-terminal linker sequence -

253 AATTCATU AAAGAGGAGAAAGGTACC and C-terminal linker sequence - 
254 GTCGACGGTATCG ATAAGCTT (in the complementary sequence, T is replaced by U

255 for pairing with A) including uracil easing direct user cloning. These four synthetized

256 gene fragments were cloned into the linear PCR fragment of pZE21 vector amplified by

257 using oligonucleotides pZE21_User-F4 and pZE21_User-R4 (Table 2) to construct pZE-

258 Gene1, pZE-Gene2, pZE-Gene3 and pZE-Gene4 recombinant plasmids, respectively.

\section{Construction of recombinant industrial Corynebacterium glutamicum strains}

261 The full metagenomics insert derived from pZE-RCL-MglE plasmid was amplified using 262 the primer pair RCL-MglE-F/RCL-MglE-R. The resulting PCR product was cloned into 263 pEKEx2 vector, using the KpnI and SacI restriction sites, yielding expression plasmid 264 pEK-RCL-MglE. The newly constructed expression plasmid was introduced into the 265 industrial L-lysine producing strain C. glutamicum VL5 by electroporation and 266 concomitant selection on kanamycin containing 2xTY-Agar. Successful construction of 267 the new strain, named C. glutamicum VL5/pEK-RCL-MglE, was verified by re-isolation 268 of the plasmid, followed by control digest and PCR on the length of the insert. The same 269 procedure was performed to introduce the empty pEKEx2 expression vector into $C$. 270 glutamicum VL5, yielding control strain C. glutamicum VL5/pEKEx2.

272 Analysis of L-lysine in supernatant of bacterial culture

273 A calibration curve of an authentic standard was generated using concentrations ranging 274 from 0.4 to $77 \mathrm{mg} / \mathrm{L}$. The accurate mass of L-lysine from 20 -fold diluted samples 275 (supernatants containing L-lysine for quantification) was analyzed using an LC-MS

276 Fusion (Thermo Fisher Scientific, USA) with positive electrospray ionization (ESI+). The

277 final concentration was adjusted for the dilution factor. Bracketing calibration was used 278 for the quantification of the external concentration. For the quantification of L-lysine, an 
279 LC-MS/MS, EVOQ (Bruker, Fremont USA) was used with multiple reaction monitoring

280 (MRM) transition in positive ionisation mode (ESI+), with the quantified transition

$281147 \rightarrow 84(\mathrm{CE} 10)$ and qualifier transition $147 \rightarrow 130$ (CE 7). The significance of the

282 specific lysine production was calculated using a Student t-test.

283

284 Results and Discussion

285 Identification of metagenomic L-lysine tolerance genes

286 The gut microbiota from industrial livestock animals are conceivably enriched with the

287 microbes capable to survive at higher L-lysine concentration which is supplied as food

288 additives. A metagenomic library derived from cow feces was constructed and used to

289 find candidate genes that could lead to a higher L-lysine tolerance in E.coli C4860 strain.

290 The resulting library was screened for L-lysine tolerance by plating on LB agar plates

291 supplemented with inhibitory concentrations of L-lysine (Fig. 1A) (materials and

292 methods). Colonies appeared only on the plates with the metagenomic library but not on

293 the control plates with E.coli C4860 harboring empty vector. Eighty L-lysine tolerant

294 clones were selected for further analysis.

295 Metagenomic inserts present in those L-lysine tolerant clones were PCR amplified,

296 sequenced and annotated using deFUME (van der Helm et al., 2015). In total, 28 unique

297 clones containing 58 complete or partial open reading frames were identified in this

298 analysis. The sequence analysis revealed that resistant clones contained orfs homologous

299 to genes encoding L-lysine modification/degradation enzymes, membrane proteins,

300 signaling proteins and hypothetical proteins. (Supplementary Table S1).

301

302 Selection of transporter candidates 
303 For the purpose of improving industrial production strains, novel efflux systems constitute

304 more relevant genetic building blocks than those involved in degradation and

305 modification, which would counteract the objective of L-lysine production. Accordingly,

306 we focused our subsequent analysis on orfs encoding potential efflux systems. We

307 identified six unique metagenomic inserts encoding putative membrane proteins, some of

308 which are annotated in Genbank as hypothetical proteins (Supplementary Table S1). Four

309 inserts were selected for further testing based on the absence of putative degradation

310 enzymes flanking the putative transporters on the metagenomic insert.

311

312 We determined the L-lysine IC90 values for each of the four selected metagenomic inserts.

313 The L-lysine IC90 values of the selected metagenomic clones ranged from $10.44 \pm 1.277$

$314 \mathrm{~g} / \mathrm{L}$ to $14.25 \pm 0.415 \mathrm{~g} / \mathrm{L}$, corresponding to a more than $40 \%$ increase in the L-lysine IC90

315 for the clone harboring pZE-RCL-MglE compared to the empty vector control strain (Fig.

316 1B). All of these strains have similar growth profiles in LB medium, whereas the growth

317 rates varied in the liquid LB supplemented with $8 \mathrm{~g} / \mathrm{L}$ of L-lysine. At $8 \mathrm{~g} / \mathrm{L}$ L-lysine

318 supplementation, the growth rate of the highest tolerant metagenomic clone harboring

319 pZE-RCL-MglE was 30\% higher than that of the empty vector control (Fig. 1C).

321 Lysine tolerance by MglE in $E$. coli strains

322 To test whether the pZE-RCL-MglE plasmid carrying the $m g l E$ gene could confer L-

323 lysine tolerance to industrially relevant $E$. coli strains, we introduced the plasmid into

324 various E. coli strains; BL21 (DE3), MG1655, Crooks, W1116, and W3110 and IC90

325 values of L-lysine were determined for all of the constructed E.coli strains. Interestingly,

326 the IC90 values of L-lysine for all of these E. coli strains were increased upon introduction

327 of the pZE-RCL-MglE plasmid (Fig. 1D). Of particular interest, the L-lysine IC90 was 
328

329

330

331

332

333

334

335

336

337

338

340

341

342

increased by $30 \%$ in W3110, which is a widely used background strain for L-lysine production (Imaizumi et al., 2005). These data demonstrate that the mechanism of Llysine tolerance mediated by pZE-RCL-MglE is effective across the industrially relevant E. coli strains and accordingly should be generally applicable to industrial E. coli-based L-lysine fermentations.

\section{Protein sequence analysis of the metagenomic insert carrying MglE}

Sequence analysis of the $1.6 \mathrm{~kb}$ PCR amplicon from pZE-RCL-MglE metagenomics insert contained an open reading frame $m g l E$ flanked by native promoter and terminator sequences (Fig. 2A). The MglE protein consists of 297 amino acids, and its closest homolog is a hypothetical protein from Bacteroides coprophilus (Genbank accession no. WP_008140691) with $82 \%$ identity at the amino acid level. The MglE protein is a member of RhaT/EamA-like transporter family of the drug/metabolite transporter (DMT; 2.A.7) superfamily. The MglE contains two copies of the EamA domain, which is found in transporters belonging to the EamA family, at 9-143 aa (pfam (Finn et al., 2014) e-value: $3 \mathrm{e}^{-11}$ ) and 152-292 aa (pfam e-value 9.6e $\mathrm{e}^{-12}$ ). The members of the EamA family are diverse, and most of their functions are unknown (Franke et al., 2003). Nevertheless, a few proteins belonging to EamA family are well characterized as exporters such as PecM exports a pigmented compound indigoidine in Erwinia chrysanthemi (Rouanet and Nasser, 2001) and YdeD export metabolites of the cysteine pathway in E. coli (Daßler et al., 2000). The predicted two-dimensional topology of the MglE transporter possesses six cytoplasmic domains, five periplasmic domains, and ten transmembrane domains, with both the $\mathrm{N}$ - and C-terminals in the cytoplasmic region (Fig. 2B). 
352 Phylogenetic analysis shows that the closest MglE homologs ( $>50 \%$ sequence identity)

353 are present in the phylum Bacteroidetes and are annotated as uncharacterized proteins

354 (Fig. 2C). Members of the LysE family (pfam id: PF01810) are mainly ( $>5$ species per

355 phyla) found in the phyla: Proteobacteria, Bacteroidetes, Firmicutes, Actinobacteria. The

356 full list of phyla that contain species with a LysE domain are Proteobacteria: 102,

357 Bacteroidetes: 73, Firmicutes: 45, Actinobacteria: 28, Chloroflexi: 1, Cyanobacteria: 3,

358 Spirochaetes: 1, Verrucomicrobia: 1 and Gemmatimonadetes: 1. Interestingly, nine

359 genomes containing the MglE homolog also contain additional LysE family (pfam id:

360 PF01810, TC code: 2.A.75) genes (Fig. 2C orange dot). MglE represents a novel L-lysine

361 transporter that could not have been identified by sequence analysis or homology to

362 known L-lysine transporters.

363

364 Effect of regions in the metagenomics insert on L-lysine tolerance

365 To investigate the effects of promoter region of the metagenomic clone on lysine 366 tolerance, the recombinant plasmids pZE-MglE ( $m g l E$ cloned into pZE21), and pZE0-P-

367 MglE-T (MglE along with its native promoter and terminator cloned into pZE21 without

368 the pLteo-1 vector promoter) were subcloned from pZE-RCL-MglE plasmid. The 369 constructed plasmids were transformed into E. coli C4860, and IC90 values of L-lysine 370 were determined (Fig. 2D). Although these recombinant C4860 strains grew in the same 371 extent in LB media, they showed different L-lysine tolerance. We observed that the IC90

372 for the strain harboring the pZE0-P-MglE-T plasmid was higher than that of the strain 373 harboring the pZE-MglE plasmid, indicating that the native promoter resulted in higher 374 lysine tolerance than the vector promoter. However, the synergistic effect of these two 375 promoters was better still (i.e., the IC90 values of the pZE-RCL-MglE plasmid was higher 376 than those of the strains harboring pZE-MglE or the pZE0-P-MglE-T plasmids). Hence, 
377 the lysine tolerance of the E. coli C4860 strain was the highest upon harboring the full

378 metagenomic insert (i.e., pZE-RCL-MglE).

379

380

\section{MgIE exports L-lysine when expressed in Xenopus oocytes}

381 For functional analysis, MglE was expressed in Xenopus oocytes and the export of C13-

382 labeled L-lysine was measured. The water-injected oocytes were used as negative control.

383 L-lysine export assay was performed by injecting C13-labeled L-lysine to obtain a final

384 cytosolic concentration of $6 \mathrm{mM}$ in the oocytes. The oocytes were incubated in Kulori

385 buffers with two different $\mathrm{pH}(\mathrm{pH} 5$ and 7.4) for $3 \mathrm{~h}$, and L-lysine concentrations were

386 measured in the buffer and within the oocytes. MglE-expressing oocytes resulted in 6.6-

387 and 8.5-fold higher extracellular concentrations of C13-labeled L-lysine and natural C12

388 L-lysine respectively than control oocytes, when buffer with pH 5 was used (Fig. 3Ai).

389 The intracellular concentrations of C13-labeled and natural C12 L-lysine were

390 correspondingly 2.1- and 1.4-fold lower than in control oocytes (Fig. 3Ai). On the other

391 hand, there was no significant change in L-lysine quantities when oocytes were incubated

392 at $\mathrm{pH} 7.4$ (Fig. 3Aii). This indicates a proton-gradient dependent export mechanism for

393 MglE transporter. L-lysine resistance (uptake) experiments in E. coli also indicated a

394 proton-dependent uptake for L-lysine because L-lysine toxicity was higher at $\mathrm{pH} 8.5$ and

39510 than at $\mathrm{pH} 4.5$ and 7 (data not shown).

397 MglE assists L-lysine export in E.coli

398 To analyze the function of MglE for L-lysine efflux, E. coli DMLC strain was constructed

399 by knocking out two lysine decarboxylase genes, constitutive (ldcC) and acid-inducible

$400(\operatorname{cad} A)$. These deletions should prevent L-lysine degradation, thereby leading to increased

401 L-lysine production (Kikuchi et al., 1997). Then, the pZE-RCL-MglE plasmid and pZE21 
402 empty vector were transformed into E. coli DMLC, yielding E. coli DMLC/pZE-RCL-

$403 \mathrm{MglE}$ and E. coli DMLC/pZE21, respectively. Subsequently, these strains along with $E$.

404 coli W3110/pZE21, were cultured in LB media as well as M9 minimal media

405 supplemented with yeast extract. The bacterial growth and extracellular L-lysine

406 concentrations were measured after $24 \mathrm{~h}$. We found that in LB media the absolute

407 extracellular L-lysine titer was increased from $744 \mathrm{mg} / \mathrm{L}$ to $806 \mathrm{mg} / \mathrm{L}$ in presence of the

408 metagenomic insert consisting MglE operon i.e. 8.3\% higher L-lysine production in the

409 E. coli DMLC/pZE-RCL-MglE strain as compared to E. coli DMLC/pZE21 in LB.

410 However, the biomass of the strain expressing MglE was decreased by about $50 \%$ as

411 compared to the control strain (Fig. 3Bi). Furthermore, the L-lysine production was

412 analysed in minimal media supplementing yeast extract. In minimal media, the

413 extracellular L-lysine accumulation was increased from $6 \mathrm{mg} / \mathrm{L}$ to $30 \mathrm{mg} / \mathrm{L}$ (p<0.0001, t-

414 test) whereas there was $12 \%$ reduced in biomass upon expressing the MglE metagenomic

415 fragment (Fig. 3Bii). The difference in extracellular L-lysine concentration among the

416 strain expressing MglE and the control strain is prominent in minimal media $\left(p<0.0001^{*}\right.$,

417 t-test) than in LB media ( $\mathrm{p}=0.1997$, $\mathrm{t}$-test). Hence, the above results demonstrate that

$418 \mathrm{MglE}$ assists exporting L-lysine from E. coli.

420 The reduced biomass might be due to the combined effect of expression of membrane

421 protein in high copy number and active export of L-lysine by MglE which could have

422 resulted in less available energy for the cell to build biomass. It is worth noting that a big

423 proportion of total cellular energy-demand is for the transport machinery which has

424 accordingly been under evolutionary selection towards a higher energetic efficiency

425 (Darbani et al., 2018). 


\section{Improvement of L-lysine productivity in industrial $C$. glutamicum strain}

428 Expression of a functionally active gene(s) from one strain to another often requires

429 special optimizations. For the practical application in industrial L-lysine bioprocesses,

430 retaining the activity of the discovered exporter into the production host, C. glutamicum,

431 is very essential. To test whether the MglE can boost the L-lysine bioprocesses, we cloned

432 and expressed it in an industrially used C. glutamicum L-lysine production strain.

434 The full metagenomic insert carrying the MglE along with its native promoter and 435 terminator was amplified from the pZE-RCL-MglE plasmid and cloned into pEKEx2 436 expression vector to construct pEK-RCL-MglE expression plasmid. The constructed 437 plasmid was introduced into C. glutamicum VL5 strain (Materials and methods), a 438 producer strain currently used for industrial L-lysine production. Using sucrose as a 439 carbon source, L-lysine production from the constructed C. glutamicum recombinant 440 strain was analyzed at $30 \mathrm{~h}$. Unlike in E.coli strains, expression of the full metagenomics 441 insert harboring MglE did not have any growth inhibition effect as the vector control and 442 the recombinant strains both have nearly equal biomass. Notably, upon incorporation of 443 the MglE operon into C. glutamicum, the specific L-lysine productivity was improved by $44412 \pm 0.07 \%$ relative to the empty vector control (Fig. 3C). By expressing the operon in 445 this highly efficient producer strain, we showed not only the functionality of the MglE in 446 a Gram-positive species but also the benefit of the efflux system on an already highly 447 optimized producer strain.

449 Comparison of L-lysine tolerance conferred by MglE and its homologous genes

450 The YbjE transporter from E. coli is one of the functionally characterized lysine-specific 451 exporters. Based upon the homology search, four genes in the NCBI database having 
452 different homologies (ranging from $43 \%$ to $82 \%$ in amino acid level) with MglE were also

453 selected and gene synthetized. To find out the lysine tolerance of MglE as compared to 454 that of $\mathrm{YbjE}$ and the four selected MglE homologous proteins (with 82, 78, 54 and 43\%

455 amino acid sequence identity), recombinant expression plasmids pZE-YbjE, pZE-Gene1, 456 pZE-Gene2, pZE-Gene3 and pZE-Gene4 were constructed. The constructed plasmids, 457 pZE-MglE and pZE21 vector control were introduced into E.coli C4860 and E.coli DMLC 458 strains and determined the IC90 of L-lysine for the constructed recombinant strains as described in early experiments.

461 Interestingly, we found that the expression of MglE provided similar L-lysine tolerance 462 in E.coli $\mathrm{C} 4860$ strain as that of YbjE whereas in E.coli DMLC strain, MglE displayed 463 even higher tolerance than YbjE. On the other hand, all of the four MglE homologs 464 showed lower lysine tolerance than MglE in both strains (Fig. 4).

\section{Conclusion}

467 We deployed functional metagenomic selections to identify novel genetic building blocks 468 encoding product efflux systems. Through applying this approach to the problem of L469 lysine toxicity at high concentration, we discovered MglE, which is confirmed as a novel 470 type of L-lysine exporter that belongs to the EamA superfamily. We demonstrate the 471 benefits of MglE in both Gram-negative (E. coli) and Gram-positive (C. glutamicum) 472 strains and show that MglE expression improves the productivity of an industrial L-lysine 473 production strain. If incorporated into industrial-scale bioprocesses, this discovery has the 474 potential to enhance L-lysine production by about $12 \%$, representing an increased profit 475 on the order of $200-500$ million USD per year. Our approach of using functional 476 metagenomics to identify novel transporters is independent of prior knowledge of 
477 transporter gene sequences and can be generally applied to most of the toxic

478 compounds/chemicals production by fermentation.

479

$480 \quad$ Protein accession numbers

481 The sequence information of full metagenomics insert harboring $m g l E$ is deposited in

482 the NCBI GenBank database with the accession number KU708839.

\section{Acknowledgements}

485 The research leading to these results was funded by the Novo Nordisk Foundation (Grant

486 Agreement no. NNF10CC1016517), and the European Union Seventh Framework

487 Programme (FP7-KBBE-2013-7-single-stage) under grant agreement no. 613745,

488 Promys. This work was further supported by the European Union Seventh Framework

489 Programme-ITN (FP7/2012/317058 to E.v.d.H). Stefan Wieschalka acknowledges

490 funding from Højteknologifonden. IB acknowledges the financial support the European

491 Research Council under the European Union's Horizon 2020 research and innovation

492 programme (YEAST-TRANS project, Grant Agreement no. 757384). We would like to

493 thank Vitalys I/S for providing the VL5 strain for lab-scale testing, Christian Munk for

494 helping with R-script to calculate IC90 values.

\section{Competing financial interests}

496 The authors declare no competing financial interests.

\section{Author contributions}

498 M.O.A.S. and S.M. conceived the study; S.M. designed and performed E.coli

499 experiments, B.D and I.B. conceived the experiments on Xenopus oocytes and B.D.

500 performed experiments. S.W. performed C. glutamicum experiments, E.v.d.H performed 
bioRxiv preprint doi: https://doi.org/10.1101/2020.04.30.071142; this version posted May 2, 2020. The copyright holder for this preprint (which

was not certified by peer review) is the author/funder, who has granted bioRxiv a license to display the preprint in perpetuity. It is made available under aCC-BY-NC-ND 4.0 International license.

501 in silico analysis. M.O.A.S., I.B., and J.F. led the research teams. M.O.A.S. and S.M.

502 drafted the manuscript and the other authors contributed to the writing.

503 


\section{References}

Archer, C.T., Kim, J.F., Jeong, H., Park, J., Vickers, C.E., Lee, S., Nielsen, L.K., 2011. The genome sequence of E. coli W (ATCC 9637): comparative genome analysis and an improved genome-scale reconstruction of E. coli. BMC Genomics 12, 9. https://doi.org/10.1186/1471-2164-12-9

Baba, T., Ara, T., Hasegawa, M., Takai, Y., Okumura, Y., Baba, M., Datsenko, K. a, Tomita, M., Wanner, B.L., Mori, H., 2006. Construction of Escherichia coli K-12 in-frame, single-gene knockout mutants: the Keio collection. Molecular systems biology 2, 1-11. https://doi.org/10.1038/msb4100050

Becker, J., Wittmann, C., 2012. Systems and synthetic metabolic engineering for amino acid production - the heartbeat of industrial strain development. Current Opinion in Biotechnology 23, 718-726. https://doi.org/10.1016/j.copbio.2011.12.025

Bellmann, A., Vrljić, M., Patek, M., Sahm, H., Kramer, R., Eggeling, L., 2001. Expression control and specificity of the basic amino acid exporter LysE of Corynebacterium glutamicum. Microbiology 147, 1765-1774.

Blattner, F.R., Plunkett, G.I., Bloch, a. C., Perna, T.N., Burland, V., Riley, M., ColladoVides, J., Glasner, D.J., Rode, K.C., Mayhew, F.G., Gregor, J., Davis, W.N., Kirkpatrick, a. H., Goeden, a. M., Rose, J.D., Mau, B., Shao, Y., 1997. The Complete Genome Sequence of Escherichia coli K-12. Science 277, 1453-1462. https://doi.org/10.1126/science.277.5331.1453

Borodina I. Understanding metabolite transport gives an upper hand in strain development. Microb Biotechnol. 2019;12(1):69-70.

Cock, P.J. a, Antao, T., Chang, J.T., Chapman, B. a, Cox, C.J., Dalke, A., Friedberg, I., Hamelryck, T., Kauff, F., Wilczynski, B., de Hoon, M.J.L., 2009. Biopython: freely available Python tools for computational molecular biology and bioinformatics. Bioinformatics (Oxford, England) 25, 1422-3. https://doi.org/10.1093/bioinformatics/btp163

Consortium, T.U., 2014. UniProt: a hub for protein information. Nucleic Acids Research 43, D204-D212. https://doi.org/10.1093/nar/gku989

Darbani B, Kell DB, Borodina I. Energetic evolution of cellular Transportomes. BMC Genomics. 2018, 19(1):418.

Darbani, B., Motawia, M.S., Olsen, C.E., Nour-Eldin, H.H., Møller, B.L., Rook, F., 2016. The biosynthetic gene cluster for the cyanogenic glucoside dhurrin in Sorghum bicolor contains its co-expressed vacuolar MATE transporter. Scientific Reports 6, 1-8. https://doi.org/10.1038/srep37079

Darbani B, Stovicek V, van der Hoek SA, Borodina I. Engineering energetically efficient transport of dicarboxylic acids in yeast Saccharomyces cerevisiae.Proc Natl Acad Sci U S A. 2019;116(39):19415-19420.

Daßler, T., Maier, T., Winterhalter, C., Böck, A., 2000. Identification of a major facilitator protein from Escherichia coli involved in efflux of metabolites of the cysteine pathway. Molecular Microbiology 36, 1101-1112. 
https://doi.org/10.1046/j.1365-2958.2000.01924.x

Elder, M. World markets for fermentation ingredients, BCC Research: Market Research Reports. 2018. FOD020E. Available online: http://www.bccresearch.com

Eikmanns, B.J., Kleinertz, E., Liebl, W., Sahm, H., 1991. A family of Corynebacterium glutamicum/Escherichia coli shuttle vectors for cloning, controlled gene expression, and promoter probing. Gene 102, 93-98. https://doi.org/10.1016/03781119(91)90545-M

Finn, R.D., Bateman, A., Clements, J., Coggill, P., Eberhardt, R.Y., Eddy, S.R., Heger, A., Hetherington, K., Holm, L., Mistry, J., Sonnhammer, E.L.L., Tate, J., Punta, M., 2014. Pfam: the protein families database. Nucleic Acids Research 42, D222D230. https://doi.org/10.1093/nar/gkt1223

Forsberg, K.J., Patel, S., Witt, E., Wang, B., Ellison, T.D., Dantas, G., 2016. Identification of genes conferring tolerance to lignocellulose-derived inhibitors by functional selections in soil metagenomes. Applied and Environmental Microbiology 82, 528-537. https://doi.org/10.1128/AEM.02838-15

Franke, I., Resch, A., Daßler, T., Maier, T., Bock, A., 2003. YfiK from Escherichia coli Promotes Export of $\mathrm{O}$-Acetylserine and Cysteine. Journal of bacteriology 185, 1161-1166. https://doi.org/10.1128/JB.185.4.1161

Gunji, Y., Yasueda, H., 2006. Enhancement of 1-lysine production in methylotroph Methylophilus methylotrophus by introducing a mutant LysE exporter. Journal of Biotechnology 127, 1-13. https://doi.org/10.1016/j.jbiotec.2006.06.003

Hayashi, K., Morooka, N., Yamamoto, Y., Fujita, K., Isono, K., Choi, S., Ohtsubo, E., Baba, T., Wanner, B.L., Mori, H., Horiuchi, T., 2006. Highly accurate genome sequences of Escherichia coli K-12 strains MG1655 and W3110. Molecular Systems Biology 2. https://doi.org/10.1038/msb4100049

Hemberger, S., Pedrolli, D.B., Stolz, J., Vogl, C., Lehmann, M., Mack, M., 2011. RibM from Streptomyces davawensis is a riboflavin/roseoflavin transporter and may be useful for the optimization of riboflavin production strains. BMC Biotechnology 11, 119. https://doi.org/10.1186/1472-6750-11-119

Imaizumi, A., Takikawa, R., Koseki, C., Usuda, Y., Yasueda, H., Kojima, H., Matsui, K., Sugimoto, S.-I., 2005. Improved production of L-lysine by disruption of stationary phase-specific rmf gene in Escherichia coli. Journal of biotechnology 117, 111-8. https://doi.org/10.1016/j.jbiotec.2004.12.014

Jensen, S.I., Lennen, R.M., Herrgård, M.J., Nielsen, A.T., 2015. Seven gene deletions in seven days: Fast generation of Escherichia coli strains tolerant to acetate and osmotic stress. Scientific Reports 5, 17874. https://doi.org/10.1038/srep17874

Käll, L., Krogh, A., Sonnhammer, E.L.L., 2007. Advantages of combined transmembrane topology and signal peptide prediction-the Phobius web server. Nucleic Acids Research 35, 429-432. https://doi.org/10.1093/nar/gkm256

Keilhauer, C., Eggeling, L., Sahm, H., 1993. Isoleucine synthesis in Corynebacterium glutamicum: Molecular analysis of the ilvB-ilvN-ilvC operon. Journal of 
Bacteriology 175, 5595-5603.

Kelle, R., Laufer, B., Brunzema, C., Weuster-Botz, D., Krämer, R., Wandrey, C., 1996. Reaction engineering analysis of L-lysine transport by Corynebacterium glutamicum. Biotechnology and Bioengineering 51, 40-50. https://doi.org/10.1002/(SICI)1097-0290(19960705)51:1<40::AIDBIT5>3.0.CO;2-0

Kikuchi, Y., Kojima, H., Tanaka, T., Takatsuka, Y., Kamio, Y., 1997. Characterization of a second lysine decarboxylase isolated from Escherichia coli . Journal of bacteriology 179, 4486-4492.

Lee, S.Y., Kim, H.U., 2015. Systems strategies for developing industrial microbial strains. Nature Biotechnology 33, 1061-1072. https://doi.org/10.1038/nbt.3365

Lutz, R., Bujard, H., 1997. Independent and tight regulation of transcriptional units in escherichia coli via the $\mathrm{LacR} / \mathrm{O}$, the TetR/O and $\mathrm{AraC} / \mathrm{I} 1-\mathrm{I} 2$ regulatory elements. Nucleic Acids Research 25, 1203-1210. https://doi.org/10.1093/nar/25.6.1203

Malla, S., Niraula, N.P., Liou, K., Sohng, J.K., 2010. Self-resistance mechanism in Streptomyces peucetius: Overexpression of drrA, drrB and $\operatorname{drrC}$ for doxorubicin enhancement. Microbiological Research 165, 259-267.

Munck, C., Albertsen, M., Telke, A., Ellabaan, M., Nielsen, P.H., Sommer, M.O. a., 2015. Limited dissemination of the wastewater treatment plant core resistome. Nature Communications 6, 8452. https://doi.org/10.1038/ncomms9452

Omasits, U., Ahrens, C.H., Müller, S., Wollscheid, B., 2014. Protter: Interactive protein feature visualization and integration with experimental proteomic data. Bioinformatics 30, 884-886. https://doi.org/10.1093/bioinformatics/btt607

Pathania, A., Sardesai, A. a., 2015. Distinct paths for basic amino acid export in Escherichia coli : YbjE (LysO) mediates export of L-lysine. Journal of Bacteriology 197, 2036-2047. https://doi.org/10.1128/JB.02505-14

Rouanet, C., Nasser, W., 2001. The PecM protein of the phytopathogenic bacterium Erwinia chrysanthemi, membrane topology and possible involvement in the efflux of the blue pigment. Journal of Molecular Microbiology and Biotechnology 3, 309 318.

Sambrook, J., Russell, D.W., 2001. Molecular Cloning : A Laboratory Manual, Third. ed. Cold Spring Harbor Laboratory Press, Cold Spring Harbor, NY.

Sommer, M.O. a, Church, G.M., Dantas, G., 2010. A functional metagenomic approach for expanding the synthetic biology toolbox for biomass conversion. Molecular systems biology 6. https://doi.org/10.1038/msb.2010.16

Sommer, M.O. a, Dantas, G., Church, G.M., 2009. Functional characterization of the antibiotic resistance reservoir in the human microflora. Science (New York, N.Y.) 325, 1128-31. https://doi.org/10.1126/science.1176950

van der Helm, E., Geertz-Hansen, H.M., Genee, H.J., Malla, S., Sommer, M.O.A., 2015. deFUME: Dynamic exploration of functional metagenomic sequencing data. BMC 
627 Research Notes 8, 328-330. https://doi.org/10.1186/s13104-015-1281-y

628 Vrljic, M., Garg, J., Bellmann, A., Wachi, S., Freudi, R., Malecki, M., Sahm, H., Lysine Exporter LysE of Corynebacterium glutamicum , a Paradyme for a Novel Superfamily of Transmembrane Solute Translocators Real-Time PCR Bioinformatics and Data. Journal of Molecular Microbiology and Biotechnology 1, 327-336.

634 Vrljic, M., Sahm, H., Eggeling, L., 1996. A new type of transporter with a new type of 
bioRxiv preprint doi: https://doi.org/10.1101/2020.04.30.071142; this version posted May 2, 2020. The copyright holder for this preprint (which was not certified by peer review) is the author/funder, who has granted bioRxiv a license to display the preprint in perpetuity. It is made available under aCC-BY-NC-ND 4.0 International license.

\section{$638 \quad$ Table legends}

639 Table 1. Bacterial strains and plasmids used in this study.

640 Table 2. Oligonucleotides used in this study.

641 
bioRxiv preprint doi: https://doi.org/10.1101/2020.04.30.071142; this version posted May 2, 2020. The copyright holder for this preprint (which was not certified by peer review) is the author/funder, who has granted bioRxiv a license to display the preprint in perpetuity. It is made available under aCC-BY-NC-ND 4.0 International license.

642 Table 1. Bacterial strains and plasmids used in this study.

\begin{tabular}{|c|c|c|}
\hline Strains/Plasmids & Description & Source/reference \\
\hline \multicolumn{3}{|l|}{ Strains } \\
\hline \multicolumn{3}{|l|}{ Escherichia coli } \\
\hline DH5 $\alpha$ & General cloning host & Invitrogen \\
\hline Top10 & Highly-efficient host for cloning and plasmid propagation & Invitrogen \\
\hline BL21(DE3) & ompT hsdT hsdS $\left(\mathrm{r}_{\mathrm{B}}^{-} \mathrm{m}_{\mathrm{B}}^{-}\right)$gal (DE3) & Novagen \\
\hline $\mathrm{C} 4860$ & Host for phage PhiX174, sup-, lambda-, F-. (now known as DSM 13127) & DSMZ \\
\hline MG1655 & $\mathrm{F}^{-1} 1^{-}$ilvG- rfb-50 rph-1 & (Blattner et al., 1997) \\
\hline W3110 & $\mathrm{F}^{-}$lambda ${ }^{-} \mathrm{IN}(\mathrm{rrnD}-\mathrm{rrnE}) 1 \mathrm{rph}-1$ & (Hayashi et al., 2006) \\
\hline W1116 & strain W and ATCC 9637 & (Archer et al., 2011) \\
\hline Crooks & E. coli ATCC 8739 & DSMZ \\
\hline BL21/pZE21 & E.coli BL21 carrying pZE21 & This study \\
\hline C4860/pZE21 & E.coli $\mathrm{C} 4860$ carrying pZE21 & This study \\
\hline MG1655/pZE21 & E.coli MG1655 carrying pZE21 & This study \\
\hline W3110/pZE21 & E.coli W3110 carrying pZE21 & This study \\
\hline W1116/pZE21 & E.coli $\mathrm{W} 1116$ carrying pZE21 & This study \\
\hline Crooks/pZE21 & E.coli Crooks carrying pZE21 & This study \\
\hline BL21(DE3)/pZE-RCL-MglE & E.coli $\mathrm{BL} 21$ carrying pZE-RCL-MglE & This study \\
\hline C4860/pZE-RCL-MglE & E.coli $\mathrm{C} 4860$ carrying pZE-RCL-MglE & This study \\
\hline MG1655/pZE-RCL-MglE & E.coli MG1655 carrying pZE-RCL-MglE & This study \\
\hline W3110/pZE-RCL-MglE & E.coli W3110 carrying pZE-RCL-MglE & This study \\
\hline W1116/pZE-RCL-MglE & E.coli $\mathrm{W} 1116$ carrying pZE-RCL-MglE & This study \\
\hline Crooks/pZE-RCL-MglE & E.coli Crooks carrying pZE-RCL-MglE & This study \\
\hline C4860/pZE-MglE & E.coli $\mathrm{C} 4860$ carrying pZE-MglE & This study \\
\hline C4860/pZE0-P-MglE-T & E.coli $\mathrm{C} 4860$ carrying pZE0-P-MglE-T & This study \\
\hline C4860/pZE-YbjE & E.coli $\mathrm{C} 4860$ carrying pZE-YbjE & This study \\
\hline C4860/pZE-Gene1 & E.coli $\mathrm{C} 4860$ carrying pZE-Gene1 & This study \\
\hline C4860/pZE-Gene2 & E.coli $\mathrm{C} 4860$ carrying pZE-Gene 2 & This study \\
\hline C4860/pZE-Gene3 & E.coli $\mathrm{C} 4860$ carrying pZE-Gene 3 & This study \\
\hline C4860/pZE-Gene4 & E.coli $\mathrm{C} 4860$ carrying pZE-Gene 4 & This study \\
\hline W3110/pSIJ8 & E.coli W3110 carrying pSIJ8 & This study \\
\hline W3110:: $\Delta \mathrm{ldcC} / \mathrm{pSIJ} 8$ & $l d c C$ deletion mutant of E.coli W3110 carrying pSIJ8 & This study \\
\hline W3110:: $\Delta \mathrm{ldcC} . \Delta \mathrm{cadA} / \mathrm{pSIJ} 8$ & $l d c C$ and $c a d A$ deletion mutant of E.coli W3110 (DMLC) carrying pSIJ8 & This study \\
\hline DMLC & $l d c C$ and $c a d A$ deletion mutant of E.coli W3110 & This study \\
\hline DMLC/pZE21 & E.coli DMLC carrying pZE21 & This study \\
\hline DMLC/pZE-RCL-MglE & E.coli DMLC carrying pZE-RCL-MglE & This study \\
\hline \multicolumn{3}{|l|}{ Kieo strain } \\
\hline b0186 & $l d c C$ replaced by kanamycin cassette $E . c o l i \mathrm{~K}-12$ BW 25113 & (Baba et al., 2006) \\
\hline b4131 & $\operatorname{cadA}$ replaced by kanamycin cassette in E.coli $\mathrm{K}-12$ BW 25113 & (Baba et al., 2006) \\
\hline \multicolumn{3}{|l|}{ Corynebacterium. glutamicum } \\
\hline VL5 & Industrial L-lysine production strain of C.glutamicum & Vitalys \\
\hline VL5/pEKEx2 & C. glutamicum VL5 carrying pEKEx2 & This study \\
\hline VL5/pEK-RCL-MglE & C. glutamicum VL5 carrying pEK-RCL-MglE & This study \\
\hline \multicolumn{3}{|l|}{ Plasmids and vectors } \\
\hline pZE21 & $\begin{array}{l}\text { E.coli expression vector with pLtet promoter, pBR322 origin of } \\
\text { replication. and kanamycin cassette }\end{array}$ & $\begin{array}{l}\text { (Lutz and Bujard, } \\
\text { 1997) }\end{array}$ \\
\hline pSIJ8 & pKD46 based vector with rhaRS-prha-FLP and ampillicin cassette & (Jensen et al., 2015) \\
\hline pUSER016 & pNB1u based vector with T7 promoter for in vitro transcription & (Darbani et al., 2016) \\
\hline pEKEx2 & $\begin{array}{l}\text { IPTG inducible C. glutamicum expression vector with kanamycin } \\
\text { cassette from pUC4 K; Ptrc, lacI, pUC } 18 \text { mcs, and pBL1 origin of } \\
\text { replications. }\end{array}$ & $\begin{array}{l}\text { (Eikmanns et al., } \\
\text { 1991) }\end{array}$ \\
\hline pZE-RCL-MglE & $\begin{array}{l}\text { pZE21 carrying L-lysine resistant metagenomic insert with MglE operon } \\
\text { from cow fecal sample }\end{array}$ & This study \\
\hline pZE-MglE & pZE21 carrying $m g l E$ gene & This study \\
\hline pZE0-P-MglE-T & $\begin{array}{l}\text { Promoter less pZE } 21 \text { carrying native promoter and } m g l E \text { gene and native } \\
\text { terminator region }\end{array}$ & This study \\
\hline pUSER016-pT7-MglE & $\begin{array}{l}\text { Codon optimized MglE gene cloned into pUSER } 016 \text { for functional } \\
\text { studies in Xenopus oocytes }\end{array}$ & This study \\
\hline pEK-RCL-MglE & $\begin{array}{l}\text { pEKEx2 carrying L-lysine resistant metagenomic insert with MglE } \\
\text { operon from cow fecal sample }\end{array}$ & This study \\
\hline pZE-YbjE & pZE21 carrying $y b j E$ gene from $E . c o l i$ BL21(DE3) & This study \\
\hline pZE-Gene1 & $\begin{array}{l}\text { pZE21 carrying gene from Bacteroides coprophilus CAG:333 having } \\
82 \% \text { identity with } m g l E\end{array}$ & This study \\
\hline pZE-Gene2 & $\begin{array}{l}\text { pZE21 carrying codon optimized gene from Bacteroides barnesiae } \\
\text { having } 78 \% \text { identity with } m g l E\end{array}$ & This study \\
\hline pZE-Gene3 & $\begin{array}{l}\text { pZE21 carrying gene from Bacteroides sp. CAG: } 770 \text { having 54\% } \\
\text { identity with } m g l E\end{array}$ & This study \\
\hline pZE-Gene4 & $\begin{array}{l}\text { pZE21 carrying codon optimized gene from Alistipes finegoldii CAG: } 68 \\
\text { having } 43 \% \text { identity with } m g l E\end{array}$ & This study \\
\hline
\end{tabular}


bioRxiv preprint doi: https://doi.org/10.1101/2020.04.30.071142; this version posted May 2, 2020. The copyright holder for this preprint (which

was not certified by peer review) is the author/funder, who has granted bioRxiv a license to display the preprint in perpetuity. It is made available under aCC-BY-NC-ND 4.0 International license.

643 Table 2. Oligonucleotides used in this study.

\begin{tabular}{lll}
\hline Primers & Oligonucleotide sequences (5'-3') & Restriction site \\
\hline pZE21_F & ATCAGTGATAGAGATACTGAGCAC & \\
pZE21_R & TTTCGTTTATTGATGCCTCTAG & \\
MglE_F & AAAGGTACCATGAGAAATTAAGTAAAAAAGC & KpnI \\
MglE_R & TTA AAGCTTCTATCTCTTTGTTACTGAAATCAT & HindIII \\
RCL-MglE-F & CGGGGTACCAAGAGGAGAAAGGTACCGGGC & KpnI \\
RCL-MglE-R & CGAGCTCCCGGGCTGCAGGAATTCG & SacI \\
YbjE_F & AAA GGTACC ATGTTTCTGGGCTGTTAATCA & KpnI \\
YbjE_R & TAT GGATCC TTACGCAGAGAAAAAGGCGAT & BamHI \\
linear_cassette F & TGCAAGGCGATTAAGTTGGGTAACGC & \\
linear_cassette R & CCATGATTACGCCAAGCTATTTAGGTGACAC & \\
For User Cloning & & \\
pZE21_User_F & & \\
pZE21_User_R & ATAAGACGGU ATCGATAAGCTTGATATCGAATTCC & \\
P-MglE-T_User_F & AGGGTACCCU CGAGGTGAAGACGAAAGGGCCTCG & \\
P-MglE-T_User_R & AGGGTACCCU GAAGTCAAGCATCTCAAAAAACTAC & \\
pZE21_User_F4 & ACCGTCTTAU TTACGATTTTACTACGGAGTATTAA & \\
pZE21_User_R4 & ATAAGCTU GATATCGAATTCCTGCAGCCC & \\
For gene deletion and confirmation & & \\
IdcC_F1 & AATGAATU CGGTCAGTGCGTCCTGCTGAT & \\
IdcC_F2 & & \\
IdcC_R & TCAGCGCCTGATGAGCTACG & \\
CadA_F1 & AGTTCTGAAAAAGGGTCACTTC \\
CadA_F2 & TCGCAATATGGTGAACCTGTT & \\
CadA_R & TGAAGTACTCCCAGATTTGGATC & \\
\hline
\end{tabular}

644 Restriction sites are indicated by underlined and italics.

645 


\section{Figure legends}

647 Figure 1. Functional metagenomic screening and Lysine tolerance of the screened metagenomics 648 clones.

649 A. Functional metagenomic screening for lysine transporters. Cow fecal metagenomic DNA library 650 construction and its functional selection for L-lysine exporters.

651 B. L-lysine IC90 values for the selected E. coli C4860 resistant clones harboring putative transporters.

652 C. The growth rates of E. coli C4860 harboring pZE-RCL-MglE and pZE21 (control) in LB-Km and LB$653 \quad \mathrm{Km}$ supplemented with $8 \mathrm{~g} / \mathrm{L}$ of L-lysine.

654 D. Improved L-lysine tolerance (IC90 values) by expression of metagenomics insert carrying MglE transporter in industrially relevant $E$. coli strains.

Figure 2. In silico analysis of the metagenomic insert contained in pZE-RCL-MglE plasmid and L-

A. The metagenomic insert present in the pZE-RCL-MglE plasmid is shown. P: promoter region, MglE: membrane bound transporter protein, and T: terminator sequence.

B. The membrane topology of the MglE transporter protein showing 6 cytoplasmic regions, 5 periplasmic regions, and 10 transmembrane $\alpha$-helices. The 15 BLASTp hits with a $>50 \%$ sequence identity were aligned to MglE and the conservation (bitscore) for each residues was calculated using the Biopython package (Cock et al., 2009).

C. A Maximum Likelihood phylogenetic protein tree containing all the significant (sequence identity $>50 \%)$ BLASTp hits in the UniProtKB database against MglE. The percentage identity of the 15 hits is shown as horizontal bars. The presence of a LysE family member in the genomes is shown with an orange dot. The highest homology with MglE is found in Bacteroides coprophilus CAG:333, with 82\% sequence identity.

D. The strategy for subcloning the MglE transporter with or without its native promoter and the resultant 
674 Figure. 3. Functional characterization of MglE transporter activity in Xenopus oocytes, E.coli and C.

675 glutamicum

676 A. L-lysine export assay of MglE transporter in Xenopus oocytes in Kulori buffer i) at pH 5 and ii) at

$\mathrm{pH}$ 7.4. The bars represent lysine contents in the oocytes or the buffer (means, \pm Std., 3-4 biological replicates each involving 20 oocytes). Significant changes are in comparison with the controls marked by asterisks $(* * p<0.01$; Fishers one-way ANOVA).

B. The extracellular L-lysine concentration of reference E. coli W3110 and its isogenic mutant strain DMLC along with the cell $\mathrm{OD}_{600 \mathrm{~nm}}$ values confirming the exporter activity of the MglE protein in i) LB media and ii) in M9 minimal media supplemented with yeast extract ( ${ }^{*} p<0.0001$, t-test).

C. Fold enhancement of specific productivity of L-lysine by MglE protein in the industrial $C$. glutamicum VL5 strain compared to the empty vector control. Error bars are s.e.m, $*$ denotes $\mathrm{p}=$

687 Figure. 4. Comparison of lysine tolerance (presented in relative IC90 values) displayed by MglE, YbjE

688 (Lysine specific exporter from E.coli) and four synthetic MglE homologs. The biomass of the strains (at 24

689 h) cultured in LB media was also shown in closed circles. 


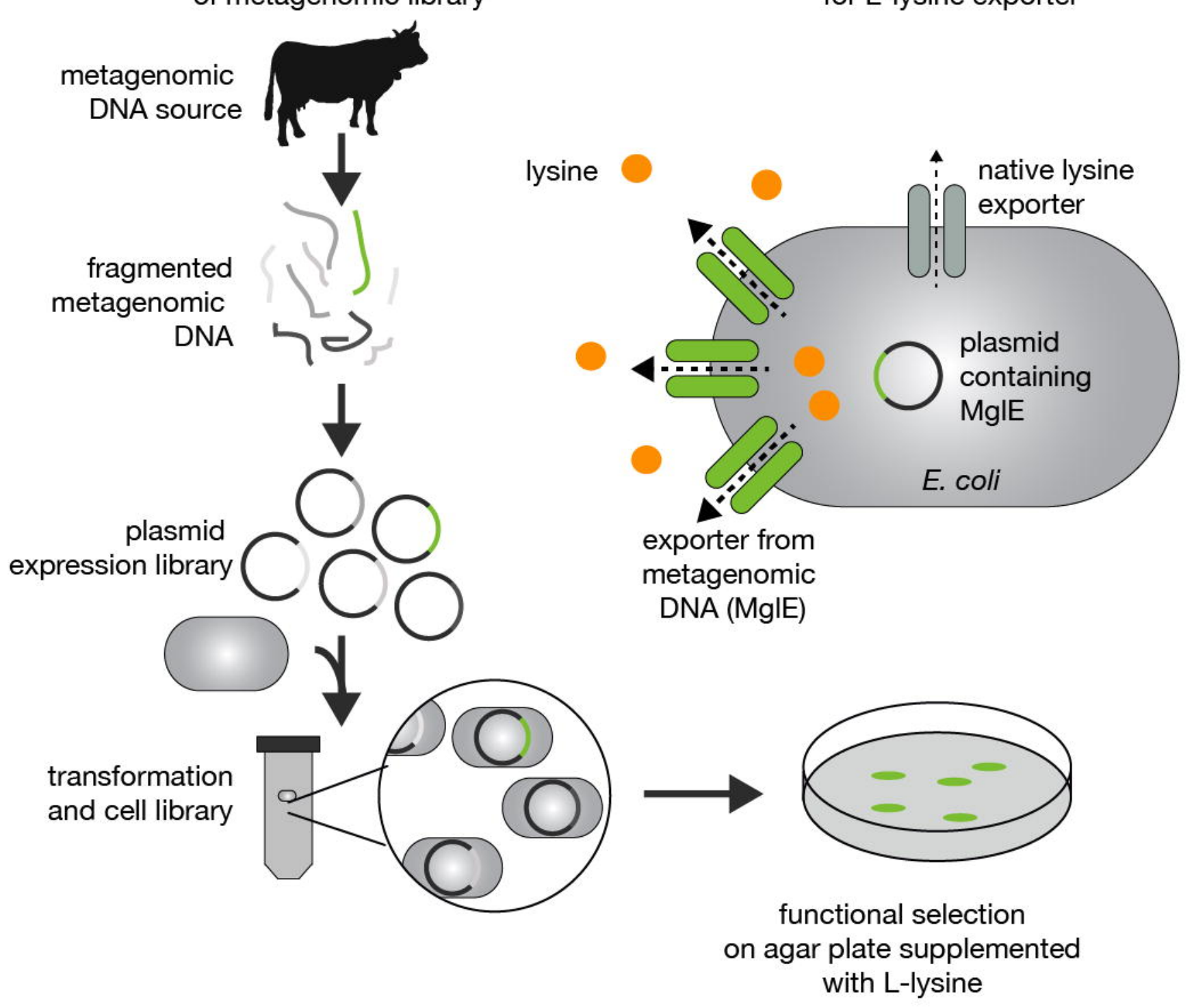

in LB media

LB $+8\left[g L^{-1}\right]$ L-lysine
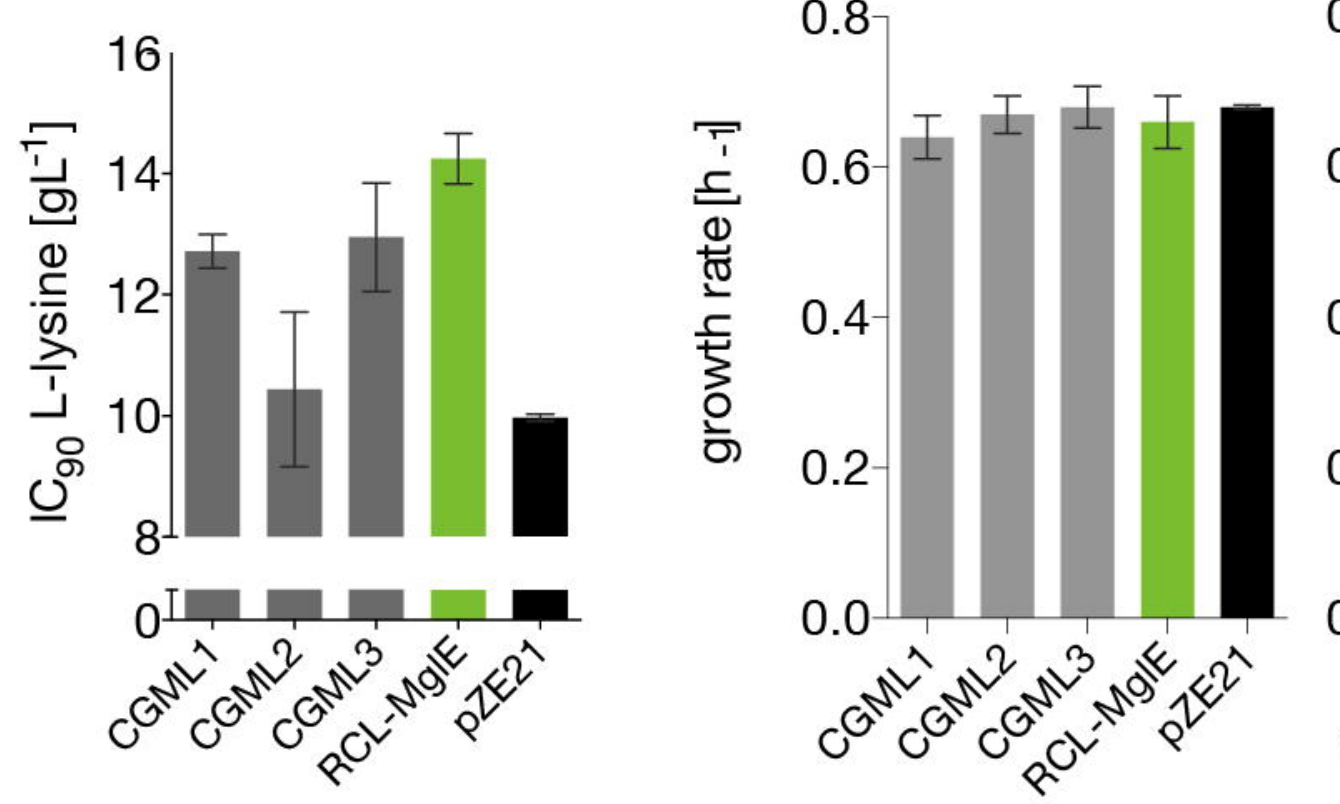
0.4

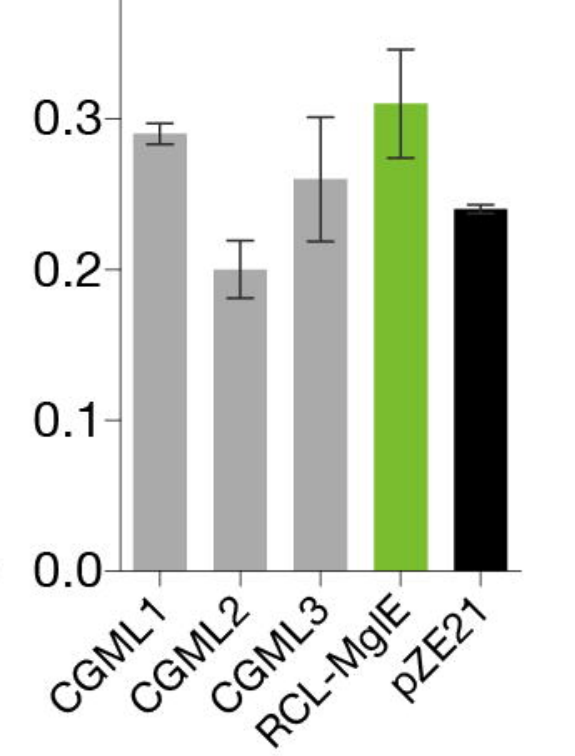

D

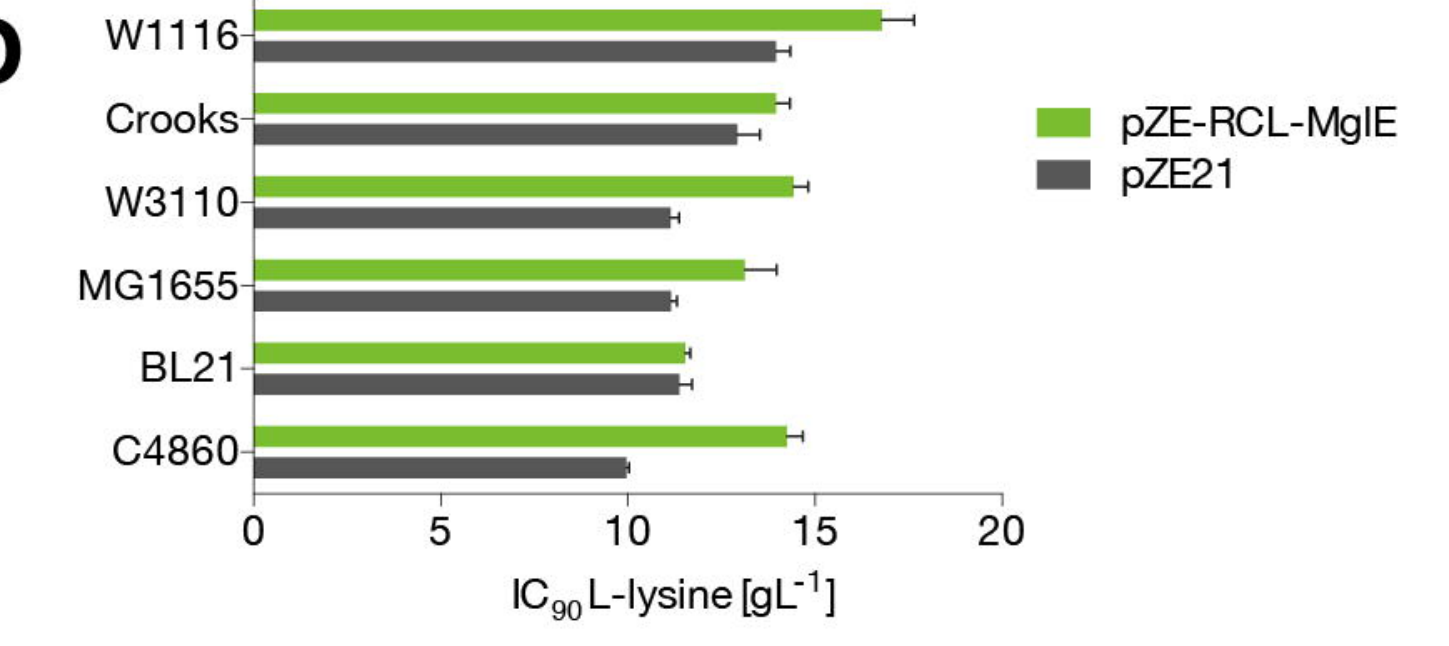


pH 5.0

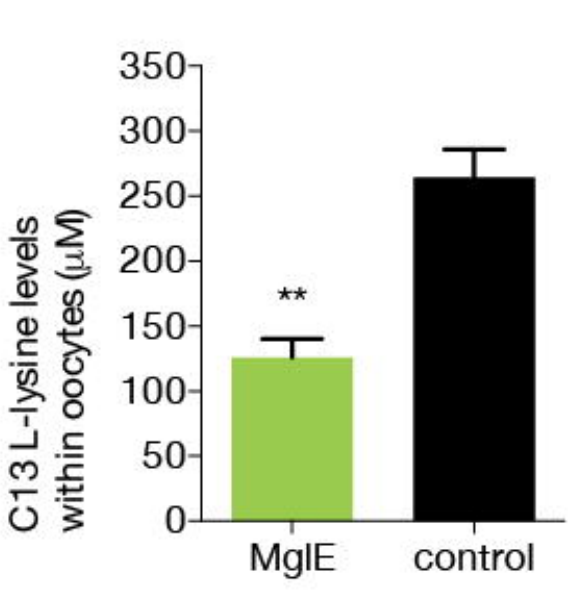

ii)

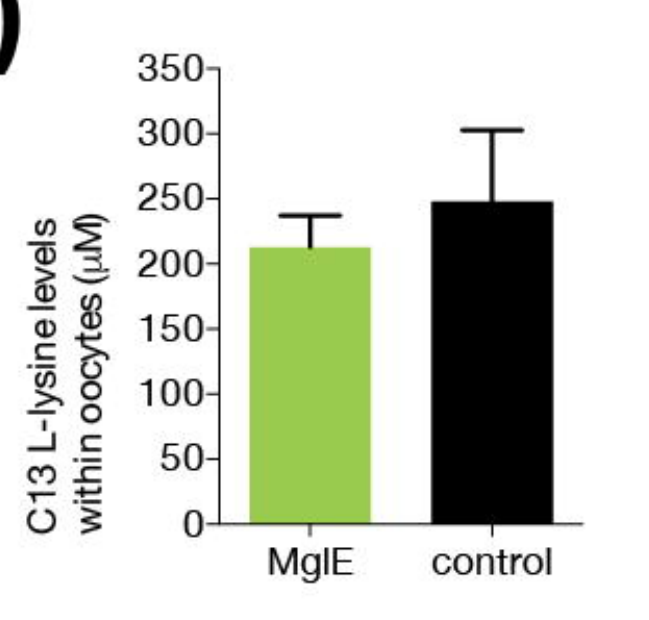

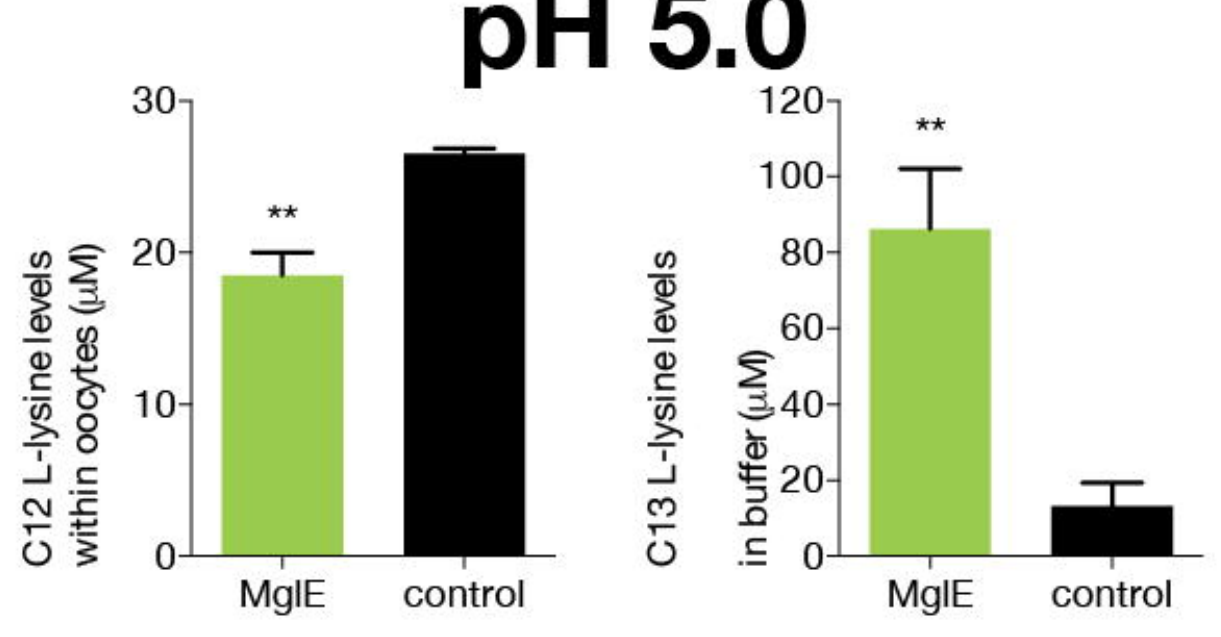

pH 7.4

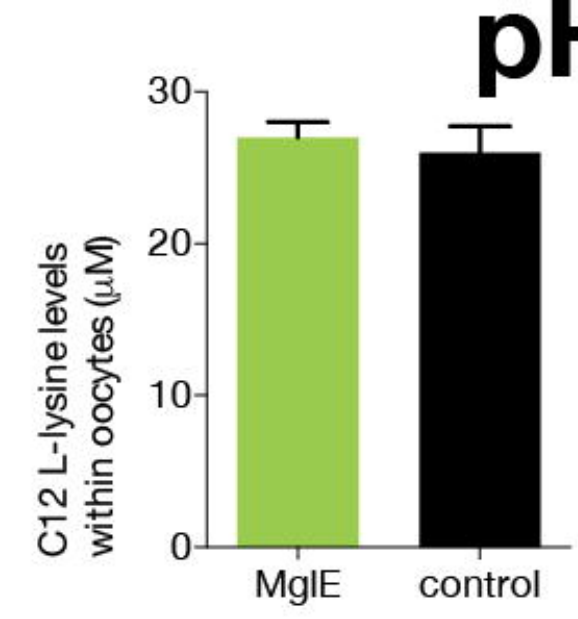

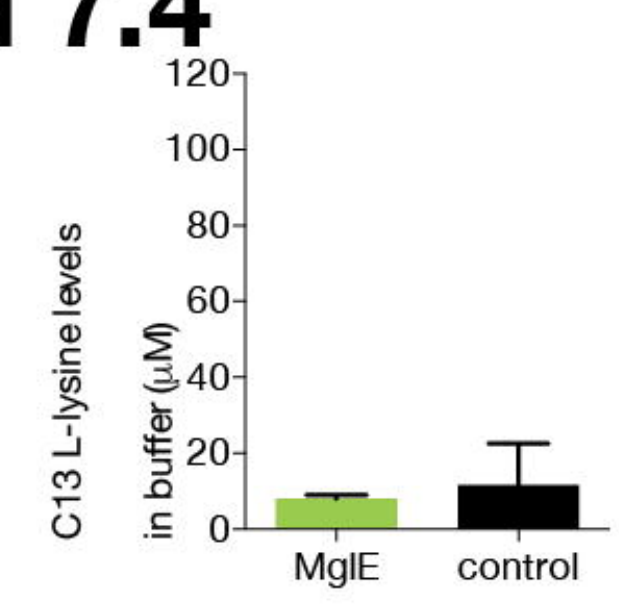

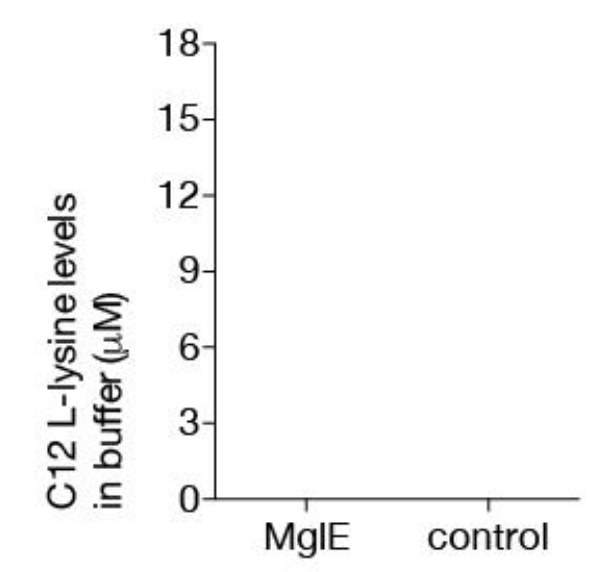

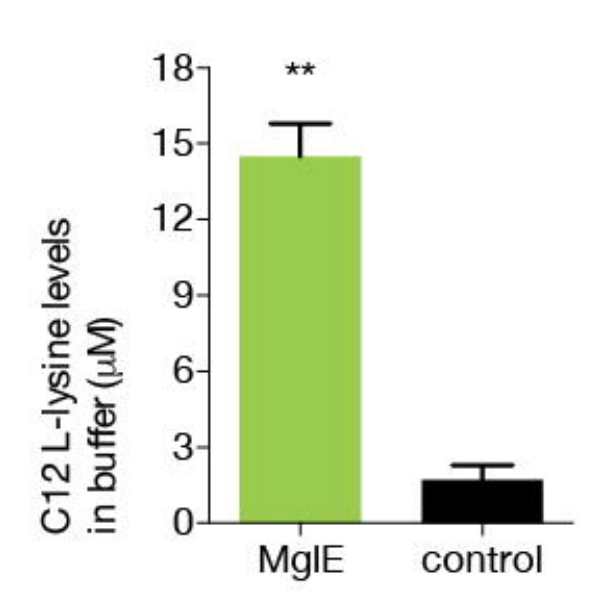

B i)

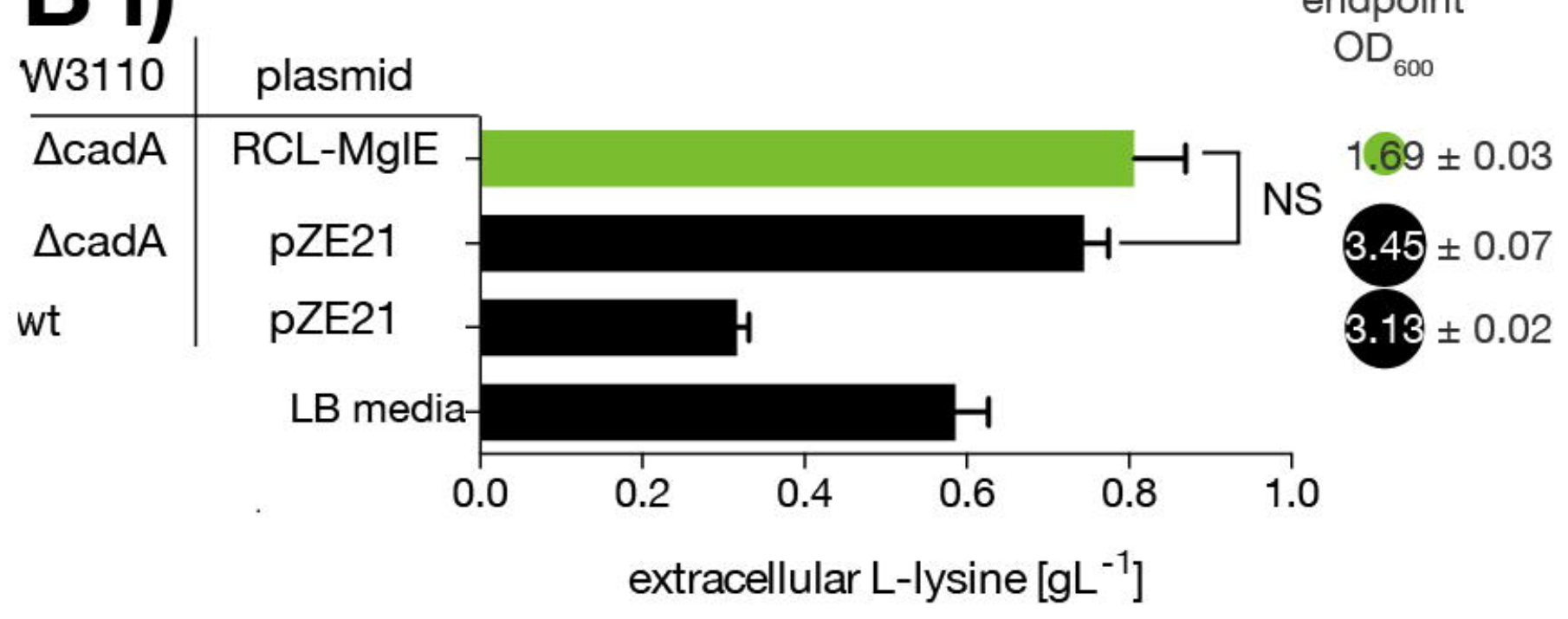

B ii)

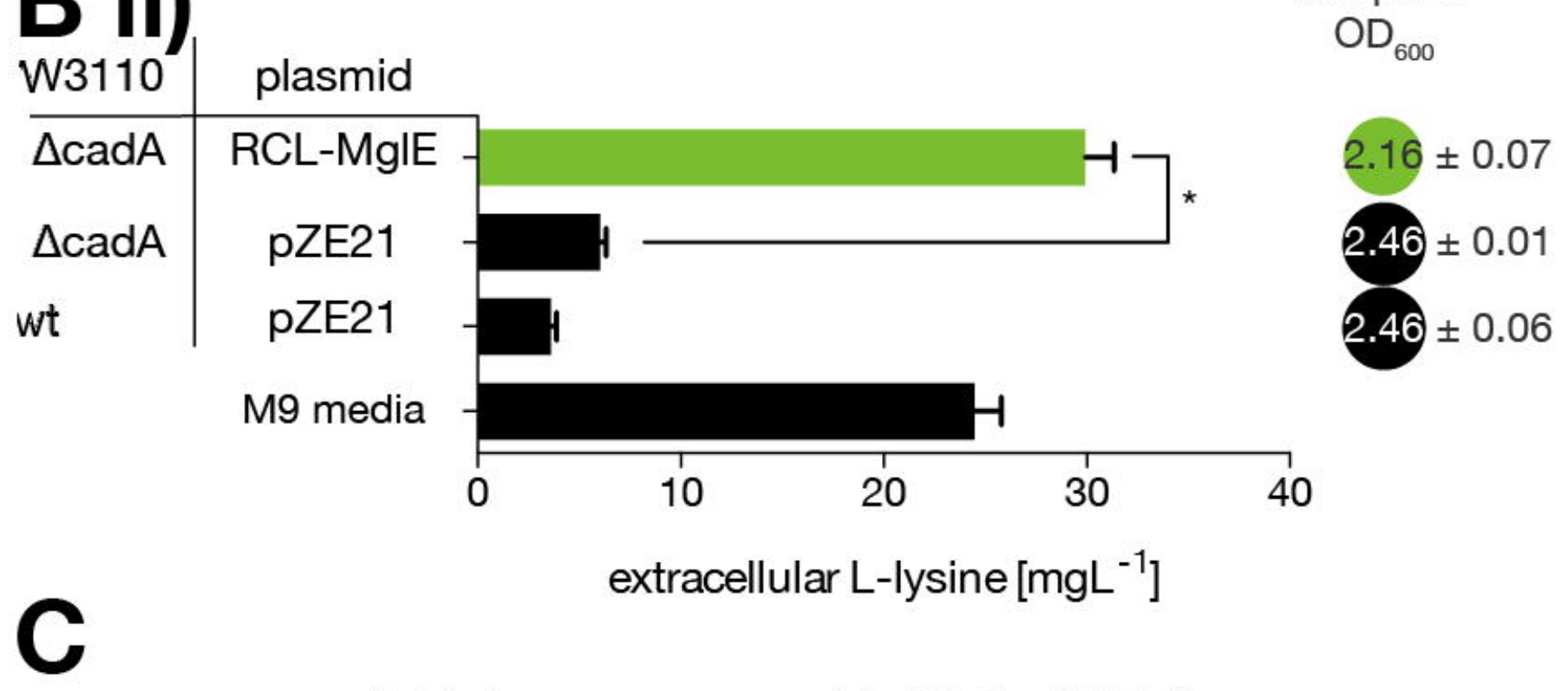

fold change compared to VL5-pEKEx2

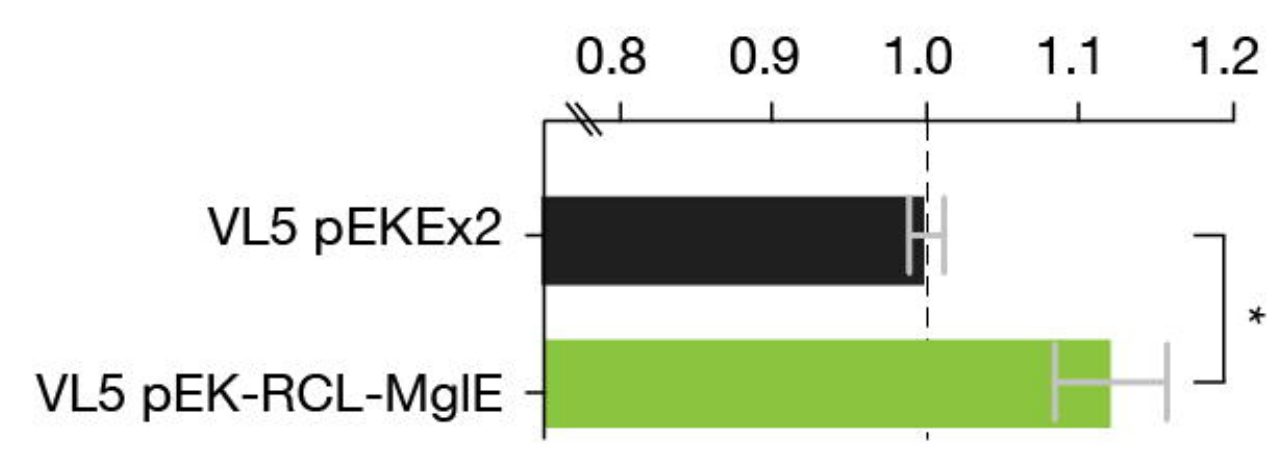


endpoint

E. coli C4860

E. coli W3110 $\Delta \mathrm{ldcC} \Delta \mathrm{cadA}$

endpoint

$\mathrm{OD}_{600}$

$3.10 \pm 0.02$

$3.15 \pm 0.02$

$3.06 \pm 0.02$

$3.09 \pm 0.03$

$3.09 \pm 0.03$

$3.13 \pm 0.09$

$3.08 \pm 0.00$

1.5

H

pZE-Gene4 (Alistipes finegoldii) pZE-Gene3 (Bacteroides sp. CAG:770) pZE-Gene2 (Bacteroides barnesiae)

pZE-Gene1 (Bacteroides coprophilus CAG:333)-

pZE-YbjE

pZE-MgIE

pZE21

1.0

0.5

0.5

fold change in $I_{90}$

$\mathrm{OD}_{600}$

$3.32 \pm 0.02$

$3.31 \pm 0.02$

$3.30 \pm 0.02$

$3.34 \pm 0.01$

$3.44 \pm 0.01$

$3.36 \pm 0.02$

$3.33 \pm 0.02$

fold change in $I_{90}$ 